\title{
Production of diseases - free plant materials of grapevine from phytoplasma in vitro
}

\author{
Viktor Klimenko ${ }^{1 *}$ Irina Pavlova $^{1}$, Vitaliy Volodin ${ }^{1}$, and Svetlana Gorislavets ${ }^{1}$ \\ ${ }^{1}$ All-Russian National Research Institute of Viticulture and Winemaking «Magarach», 31 str. Kirova, \\ Yalta, Republic of Crimea, 298600, Russia
}

\begin{abstract}
Heat treatment was used as a method of improving the health of grape plants from the phytoplasma. The Binder KBWF 240 growth cabinet was used for thermotherapy, in which plants of the Tsitronny Magaracha variety were cultivated in vitro under simulated conditions with a treatment period of 14 days. The results of repeated testing of samples showed the efficacy of treatment of this grape disease: out of 13 samples of the Tsitronny Magaracha variety, only one revealed the latent form of phytoplasma blackening of grapevine wood Bois noir. To improve the health of grape plants obtained in vitro culture, it is advisable to use the developed technological operations with thermotherapy in the growth cabinet, which allows to rid the planting material of the latent form of phytoplasma associated with blackening of grapevine wood Bois noir.
\end{abstract}

\section{Introduction}

Phytoplasmas have spread in many countries, causing significant damage and raising serious concern in vineyards and phytopathological services. In recent years significant advances have been made in the diagnosis, etiology and epidemiology of phytoplasmic diseases [1-5]. Control of the sanitary condition of young plans, elimination of infected plants and treatment of vineyard with insecticides against leafhopper-vectors form the basis of measures to reduce the spread of phytoplasmas. The protection from the disease of Grapevine Yellows (GY) (Grape vine flavescence dorée phytoplasma) consists in chemical treatment against the vector (Scaphoideus titanus Ball.), which is not suitable for control the disease of grapevine black wood (Bois noir) [6]. The prevalence of diseases is facilitated by the propagation of infected plants in grape nurseries. Therefore, measures are being taken to develop protocols for the production of phytoplasma-free grape planting material.

Tissue culture methods are usually used to eradicate viruses and viroids [7-9], however, reports have been published about their potential for phytoplasm elimination [10, 11]. These methods are used both to sustention the pathogen in host plants in order to create a collection of strains, and to eliminate phytoplasma from diseased plants. Hot water treatment has been proposed for the treatment of plant material phytoplasma at dormancy [6], but this therapy

\footnotetext{
${ }^{*}$ Corresponding author: vik klim@rambler.ru
} 
reduces the viability of grafted grape young plants. Tissue culture methods used in combination with the heat treatment are successfully used to eliminate viruses in grapes [1216], but the possibilities of these procedures for improving from phytoplasma are far less studied. The efficacy of tissue cultivation methods in combination with thermotherapy for producing Chardonnay young plants without phytoplasma associated with blackening of grapevine wood is reported [10]; all the studied protocols were suitable for the elimination of phytoplasma, providing complete recovery of shoots.

Since vineyards affected by blackening of grapevine wood are quite widespread, the protection from this disease by developing the protocol for obtaining planting material without phytoplasma has become a major trend. The purpose of this research is biotechnological aspects of improving grape varieties and clones from phytoplasmas.

\section{Material and method}

Material for research - plants in vitro of the Tsitronny Magaracha grape variety. Samples of the Tsitronny Magaracha variety were introduced to in vitro culture and reproduced. The ligneous vine was sprouted indoor to obtain the primary material. The developed shoots were cut into 1-2 buds explants, then placed in weighing vessel for disinfection. Disinfection was carried out with $96 \%$ rectified ethyl alcohol over 40 seconds. and diacid for 8 minutes, followed by 3 -fold washing with autoclaved distilled water for 15 minutes.

Explants were introduced in modified MS culture medium containing 6benzylaminopurine (BAP) at a concentration of $0.4-0.6 \mathrm{mg} / \mathrm{l}$. The generated shoots for rooting were transplanted to the $\mathrm{H}_{2}$ medium containing $0.08 \mathrm{mg} / \mathrm{l}$ of $\alpha$-naphthylacetic acid. The formed plants were propagated by microshooting. The plants were cultivated on $\mathrm{H}_{2}$ medium at a 16-hour photoperiod with the intensity of $1500 \mathrm{~lx}$ and the temperature of $+27{ }^{\circ} \mathrm{C}$.

The Binder KBWF 240 growth cabinet was used for thermotherapy, where in vitro grape plants of the Tsitronny Magaracha variety were cultivated under simulated conditions with the treatment period of 14 days. Intact plants were cultivated in the previously developed mode of thermotherapy.

Samples were tested for the presence of a latent form of phytoplasma. Testing of phytoplasma blackening of grapevine wood (Bois noir) was performed by nested PCR with specific primers for PCR 1: FD9f1 and FD9r1. PCR 1 - products were diluted 1000 times and PCR2 was performed with primers: FD9f3b and FD9f3r2.

\section{Results and Discussion}

The results of preliminary testing of plants in vitro of the Tsitronny Magaracha grape variety sent on examining showed the presence of a latent form of phytoplasma associated with blackening of grapevine wood (Bois noir) in the samples. The material was selected in the amount of 13 samples for health improvement after several passages on similar medium. The heat treatment was used as a method of improving plants from phytoplasma. After two weeks of cultivation in the growth cabinet in the mode of thermotherapy, the condition of the plants was satisfactory, the shoots and root system were not affected (Figure 1). 


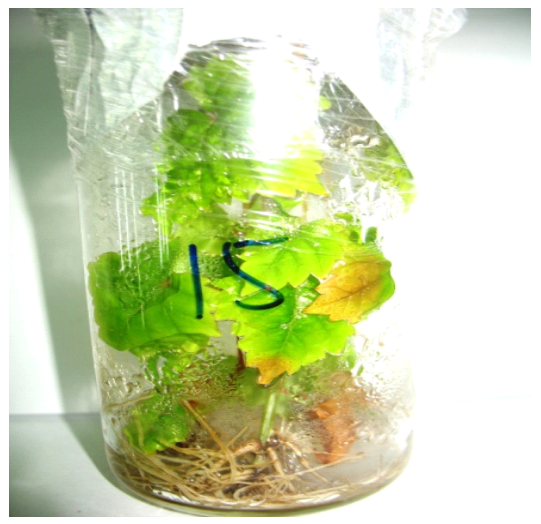

Fig. 1. Plant of Tsitronny Magaracha variety after thermotherapy (sample 15).

The tops of plants with the length of 2-3 cm were transplanted to the $\mathrm{H}_{2}$ medium of a similar composition after thermotherapy. Then material was taken from these plants for repeated testing for the presence of phytoplasma. The results of repeated testing of samples showed the efficacy of treatment of this grape disease: out of 13 samples of the Tsitronny Magaracha variety, only one revealed the latent form of phytoplasma grapevine black wood Bois noir (Figure 2).

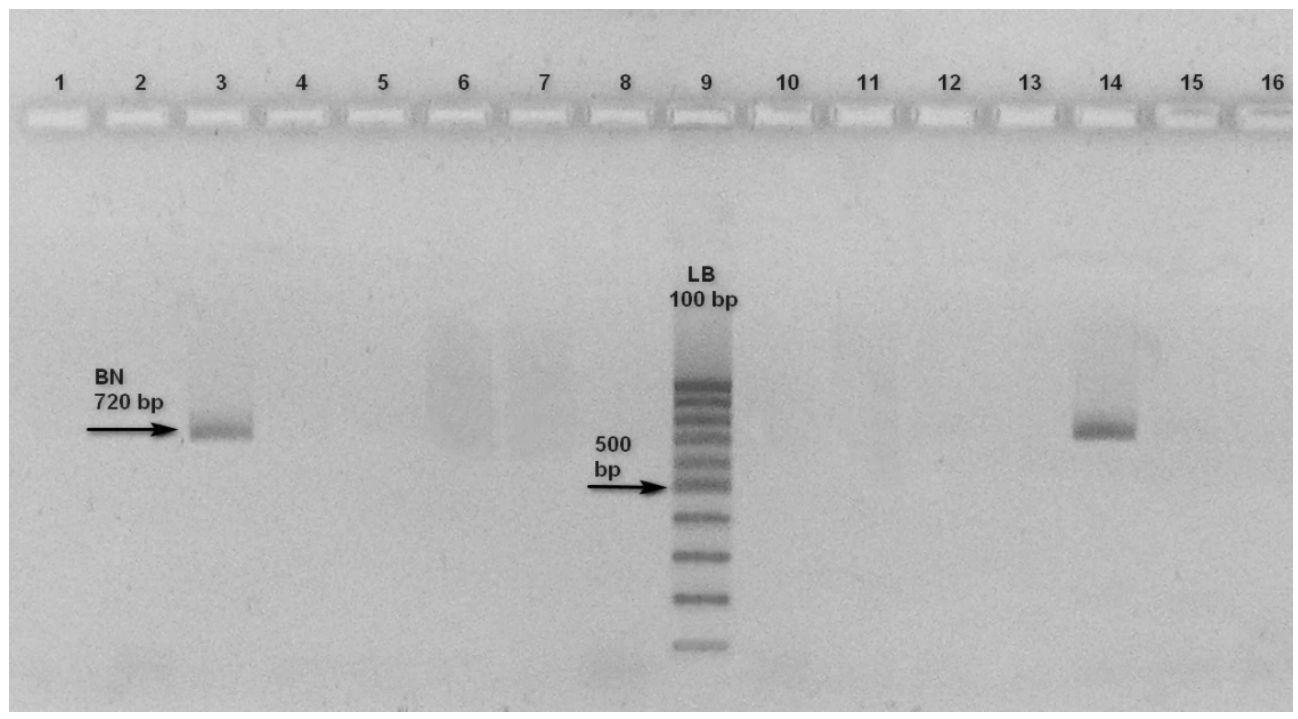

Fig. 2. Electrophoregram reflecting the results of repeated testing of samples of the Tsitronny Magaracha variety after thermotherapy: 1, 2, 10-12 - samples in which the pathogen of black wood was not detected; 3 - PCR amplicon of grapevine black wood phytoplasm was detected (720 bps); 9 Lb 100 bp; 14 - positive control of black wood (720 bps); 15, 16 - negative control.

The amplicon of phytoplasma blackening of grapevine wood was detected in wells 3 (test sample) and 14 (positive control, $720 \mathrm{bps).} \mathrm{The} \mathrm{Pathogen} \mathrm{of} \mathrm{blackening} \mathrm{wood} \mathrm{was} \mathrm{detected}$ in well 3 (sample № 10 of the Tsitronny Magaracha variety).

The results obtained in this work are encouraging, if anything, they can be verified by further research. In addition, it remains to be assessed whether the recovered samples will remain asymptomatic. 
The hypothesis that the phytoplasma of Grapevine Yellows (Grape vine flavescence dorée phytoplasma) can not significantly infect grape plants cultivated in vitro leads to the idea that clonal micropropagation itself should be considered as a method of improving. The situation is different with the phytoplasma blackening of grapevine wood (Bois noir), which is usually detected during micropropagation, but still its stability into in vitro culture should be tested experimentally. Therefore, it is preferably to have additional concepts of phytoplasma elimination.

According to the obtained results and reports from other authors $[10,17,18]$, the protocol based on tissue culture in combination with heat treatment followed by micropropagation of healthy plants seems to be the most practical. This approach can become a routine method of producing grape young plants free of the phytoplasma associated with blackening of grapevine wood Bois noir, as part of the planting material and mother planting certification programs. It is advisable to use the developed technological procedures with the use of plant thermotherapy in vitro to improve the grapes planting material from the latent form of phytoplasma.

\section{References}

1. G. Belli, P. A. Bianco, M. Conti, JPP, 92(2), 303-326 (2010). 10.4454/jpp.v92i2.172. https://www.sipav.org/main/jpp/index.php/jpp/article/view/172

2. N. Contaldo, Z. Soufi, A. Bertaccini, Bull. Insectology, 64, 217-218 (2011). https://pdfs.semanticscholar.org/37dd/5eb33705c63a6788109570479253568e2ee7.pdf

3. A. Fabre, J. L. Danet, X. Foissac, Gene, 472(1-2), 37-41 (2011). https://doi.org/10.1016/j.gene.2010.10.012

4. S. Murolo, C. Marcone, V. Prota, R. Garau, X. Foissac, G. Romanazzi, J. Appl. Microbiol., 109(6), 2049-2059 (2010). https://doi.org/10.1111/j.1365$\underline{2672.2010 .04835 . \mathrm{X}}$

5. M. Riedle-Bauer, K. Hanak, F. Regner, W. Tiefenbrunner, J. Phytopathology, 158(9), 628-632 (2010). https://doi.org/10.1111/j.1439-0434.2009.01659.x

6. M. Kölber, Int. J. Hortic. Sci., 17(3), 37-43 (2011). https://doi.org/10.31421/IJHS/17/3/955

7. N. Boonham, J. Kreuze, S. Winter, R. van der Vlugt, J. Bergervoet, J. Tomlinson, R. Mumford, Virus Res., 186, 20-31 (2014). https://doi.org/10.1016/j.virusres. 2013.12.007

8. A. Panattoni, A. Luvisi, E. Triolo, Span. J. Agric. Res., 11(1), 173-188 (2013). https://doi.org/10.5424/sjar/2013111-3201

9. G. Gambino, B. Navarro, R. Vallania, I. Gribaudo, F. Di Serio, Eur. J. Plant Pathol., 130(4), 511-519 (2011). https://doi.org/10.1007/s10658-011-9770-x

10. L. Chalak, A. Elbitar, N. Mourad, C. Mortada, E. Choueiri, Adv. Crop Sci. Tech., 1, 107 (2013). https://doi.org/10.4172/2329-8863.1000107

11. L. Chalak, T. Elbeaino, M. Elbitar, T. Fattal, E. Choueiri, Phytopathol. Mediterr., 54(3), 531-535 (2015). https://doi.org/10.14601/Phytopathol_Mediterr-16088

12. G. Hu, Y. Dong, Z. Zhang, X. Fan, F. Ren, J. Zhou, Plant Cell. Tiss. Org. Cult., 121, 435-443 (2015). https://doi.org/10.1007/s11240-015-0714-6

13. G.-J. Hu, Z.-P. Zhang, Y.-F. Dong, X.-D. Fan, F. Ren, H.-J. Zhu, Australasian Plant Pathol., 44, 167-173 (2015). https://doi.org/10.1007/s13313-014-0334-3 
14. M. Laimer, M. Barba, In: A. Hadidi, M. Barba, T. Candresse, W. Jelkmann (eds.), Virus and virus-like diseases of pome and stone fruits, (Virology, 389-393, 2011). https://doi.org/10.1094/9780890545010.065

15. A. Panattoni, E. Triolo, Sci. Hortic., 125(1), 63-67 (2010). https://doi.org/10.1016/j.scienta.2010.03.001

16. M.-R. Wang, Z.-H. Cui, J.-W. Li, X.-Y. Hao, L. Zhao, Q.-C. Wang, Plant Methods, 14, 87 (2018). https://doi.org/10.1186/s13007-018-0355-y

17. H. Linck, C. Lankes, E. Krüger, A. Reineke, Plant Dis., 103(6), 1252-1255 (2019). https://doi.org/10.1094/PDIS-08-18-1372-RE

18. G.R. Smith, J.D. Fletcher, V. Marroni, J.M. Kean, L.D. Stringer, J. Vereijssen, Australasian Plant Pathol., 46, 277-284 (2017). https://doi.org/10.1007/s13313-017$\underline{0489-9}$ 